\title{
THE OUTCOMES OF BONE MARROW STROMAL CELL THERAPY IN SCHISTOSOMAL HEPATIC FIBROSIS: AN EXPERIMENTAL STUDY
}

\author{
By \\ DINA M. ABOU RAYIA ${ }^{1 *}$ SIRRIA M. ELMARHOUMY ${ }^{1}$, HOWAIDA H. ISMAIL ${ }^{1}$, \\ FARHA A. ELCHENNAWY ${ }^{2}$ AND KHALED R. ZALATA ${ }^{3}$ \\ Department of Parasitology ${ }^{1}$, Faculty of Medicine, Tanta University, Departments of \\ Clinical Pathology ${ }^{2}$, and Histopathology ${ }^{3}$, Faculty of Medicine, Mansoura University, \\ Egypt (*Correspondence:dina_aboraya@yahoo.com. Tel.: +2 (011) 44895025)
}

\begin{abstract}
Liver fibrosis is considered a serious health problem. Liver transplantation is almost the only curative treatment. The limited number of donors and the post-operative complications are major obstacles. Recent reports have shown that mesenchymal stem cells could improve chemically-induced hepatic fibrosis. The purpose of the present study was to evaluate the effect of bone marrow stromal cells (BMSCs) transplantation on hepatic fibrosis in Schistosoma mansoniinfected mice. Female mice infected with $S$. mansoni were divided into three test groups. One group received praziquantel drug orally. Another group received BMSCs, obtained from male mice, by intravenous injection. The last group received both. Two control groups were used, one was infected and untreated and the other was uninfected and untreated. Detection of BMSCs hepatic engraftment, morphometric analysis and histopathological evaluation of liver fragments, were done. Level of interleukin-10 (IL-10) mRNA expression was assessed. The results showed that BMSCs engrafted into the liver. There was significant improvement in morphometric and histopathological evaluation of liver fragments, and increase in IL-10 mRNA expression of all treated modalities. Promising result was achieved when BMSCs and PZQ used in treated mice.
\end{abstract}

Keywords: Stem cells; Bone marrow stromal cells; Mesenchymal stem cells; Schistosoma mansoni; Schistosomiasis; Liver fibrosis.

\section{Introduction}

Liver fibrosis is considered a serious worldwide public health problem (Friedman, 2003). Whatever its cause, there is to date no specific therapy for this disease and patients only receive treatment for its associated complications. Hence, the development of an effective therapy for hepatic fibrosis is a major aim of medical research (Saez-Lara et $a l$, 2006). Schistosomiasis, among liver fibrosis different etiologies, is considered an important leading cause of hepatic fibrosis and portal hypertension especially in the developing countries, contributing to death of over half million people a year (Abdel Aziz et al, 2012). It also represents the second most important parasitic disease with a detrimental socioeconomic impact on more than 200 million people living in these countries (Farid et al, 2005).

Chemotherapy is an effective treatment that helped dramatically in decreasing the incidence of schistosomiasis. However, it doesn't prevent re-infection and has a little effect on the already developed hepatosplenic complications (Mbaye and Appleton, 2001). So, currently, the almost only curative treatment for patients who develop advanced hepatic fibrosis is liver transplantation. Unfortunately, most patients are unable to undergo transplantation due to limited availability of donors' livers. Many patients die while waiting for liver transpla-nts (Freeman et al, 2008).

New therapeutic strategies aiming to minimize damages caused by hepatic fibrogenesis in chronic liver diseases are of great interest (Oliveira et al, 2008). The new era of stem cell therapy has shown promising benefits in experimental models of hepatic diseases caused by drug administration (carbon tetrachloride-induced fibrosis) (Fang et al, 2004), surgical interventions (bile duct ligation-induced biliary cirrhosis) (George et al, 2005) or by genetic disorders as tyrosinemia (Wu et al, 2011).

Hepatic fibrosis due to experimental infection with Schistosoma mansoni is a model 
that reflects the human form of the disease to a great extent. In the mouse model of schistosomiasis, the main immune-inflammatory response is directed against the parasite eggs which when swept to the portal circulation cause periportal hepatic fibrosis which resembles the pipe-stem fibrosis found in severe hepatosplenic form of the disease in human (Andrade and Cheever, 1993). In the present study, we used an experimental model of hepatic fibrogenesis caused by chronic infection with $S$. mansoni in order to evaluate the potential therapeutic effect of transplanted bone marrow-derived stromal cells (BMSCs).

\section{Materials and Methods}

Animals: Male and female Swiss Albino mice (4-6wk old) were used as donors and recipients of BMSCs respectively. Male mice donors were used to be able to detect cell engraftment into the recipient female livers by PCR analysis of the Y male chromosome. Animals weighting (20-30g) were kept in the Medical Experimental Research Center of Mansoura University, under controlled conditions of temperature $\left(22 \pm 2^{\circ} \mathrm{C}\right)$, humidity $(55 \% \pm 10 \%)$ and air renovation. Animals were housed in a $12 \mathrm{~h}$ light $/ 12 \mathrm{~h}$ dark cycle (6am-6pm) and allowed normal rodent diet and water ad libitum. Animals were dealt with the National Guidelines for Animal Experimentation.

Mice infection with Schistosoma mansoni: Infected Biomphalaria alexandrina were obtained from the Biological Unit TheodorBilharz Research Institute, Giza. Cercarial shedding was done and female mice were infected with $60 \mathrm{~S}$. mansoni cercariae/mouse via subcutaneous injection in the thigh (Elkhafif et al, 2010). Infection was confirmed 6 weeks post injection by examination of feces for eggs, and those with viable eggs were used in the experiment.

Experimental design: Infected female mice were divided into two main groups; GI: control infected and non-treated and GII: infected treated and subdivided into three subgroups: group GIIa treated with PZQ drug orally that was available as Biltricide (Bayer) $600 \mathrm{mg}$ tablets. It was given in a dose of $500 \mathrm{mg} / \mathrm{kg} / \mathrm{dose}$ in two doses; one was given six weeks post infection and second dose after nine days (Ismail et al, 2001). GIIb treated with $10^{6}$ BMSCs eight weeks post infection via intravenous injection into the tail vein (Cho et al, 2009). GIIc given PZQ \& BMSCs. GIII: Normal control was neither infected nor treated. Each mice group consisted of 20 mice and all mice groups were kept under the same laboratory conditions.

Preparation \& transplantation of BMSCs: Femurs and tibiae of male mice were harvested and thoroughly cleaned of all muscle tissues. According to the method described by Dobson et al. (1999), the bone marrow was flushed from the medullary cavities using 25-gauge-needle with Dulbecco's Modified Eagle Medium (DMEM) into a centrifuge tube. The cell suspension was centrifuged at $1200 \mathrm{rpm}$ for 5 minutes then the supernatant was removed and the pellet was suspended in $3 \mathrm{ml}$ media followed by filtration through a 70- $\mu$ m nylon mesh filter. The cells were cultured in DMEM supplemented with $10 \%$ fetal bovine serum, $1 \%$ penicillin/streptomycin and 2mM L-glutamine (all from Gibco). The culture flasks were maintained at $37^{\circ} \mathrm{C}$ in a $5 \% \mathrm{CO} 2$ incubator for about 24 hours (Fig. 1A). Then, the nonadherent cells were removed leaving only adherent cells to which fresh media was added. At approximately $80 \%-90 \%$ confluence (Fig. 1B), cells were detached from the culture flasks using $0.25 \%$ trypsin-EDTA and re-plated. The cells were purified up to four passages, then detached, checked for viability using trypan blue and counted using the haemocytometer in the 4 squares used for WBCs count where the number of viable cells $/ \mathrm{ml}=$ number of viable cells counted in the 4 squares $\times$ dilution factor $\times$ 10.000. Finally, $10^{6}$ cells were injected I.V. into the tail vein of each mouse.

Male-specific Sry gene detection in female mice livers: To confirm the presence of male donor-derived cells in the livers of female 
recipient mice, polymerase chain reaction (PCR) analysis of sex determination region on the Y chromosome (male-specific Sry gene) was carried out. Ten weeks post infection, mice were subjected to euthanasia with ketamine and xylazene, and their livers were taken. DNA extraction was done using DNA extraction kit (QIAamp ${ }^{\circledR}$ DNA Mini Kit). DNA amplification was done using Taq PCR Master Mix Kit all was supplied by QIAGEN, Germany. Mice-specific Sry gene primers according to Fang et al. (2004) were (5 CAGCTAACACTGATCTTTTC3`) and (5'TTACTGAGCCAGAATCATAG3`). Amplified products of PCR were detected by gel electrophoresis.

Histopathological estimation of hepatic granulomas size: Paraffin blocks were made from the livers previously fixed in $10 \%$ formol-saline. Serial $(5 \mu \mathrm{m})$ sections were cut from each sample. The sections were stained with haematoxylin and eosin and with Masson's trichrome stain. The diameter of hepatic granulomas was measured using the fully automated Leica Image Processor with automated stage and the Leica Quin software 2004. Five randomly selected microscopic fields / liver section were examined at $40 \mathrm{X}$ magnification. Three liver sections for each mouse were examined. The hepatic granulomas mean diameter was determined (Ali and Hamed, 2006).

Determination of the inflammatory reactions density: The density of inflammatory reaction within the hepatic granulomas was determined (Botros et al, 2007), using a modified semi-quantitative histologic evaluation of inflammatory cellular infiltrate in five microscopic fields of highest inflammatory intensity at magnification 40x: Grade 0: no inflammation, Grade I: minimal $(\leq 25$ $\%)$, Grade II: mild (26-50\%), Grade III: moderate (51\%-75\%) and Grade IV: marked $(>75 \%)$.

Determination of hepatic parenchymal necrosis: Hepatic parenchymal necrosis was assessed (Ishak et al, 1995). The presence of visible small necrotic foci in the hepatic pa- renchyma away from the granuloma areas in five randomly selected fields at magnification 10x and expressed due to the severity as follows: Grade 0: no necrosis, Grade I: minimal $(<2$ necrotic foci/lobule), Grade II: mild (2-5 necrotic foci/lobule), Grade III: moderate (6-10 necrotic foci/lobule) \& Grade IV: marked ( $>10$ necrotic foci/lobule).

Morphometric assessment of liver fibrosis (Abdalla et al, 2009): the area of liver fibrosis was quantitated in percentage in Masson's trichrome stained liver sections using automated Leica image processor with automated stage and Leica Quin software 2004. Briefly, the liver section slide stained with Masson's trichrome was placed on the motorized stage of Leica microscope. At a magnification of $10 \mathrm{X}$, automated sequential digitalized images were taken, converted into a binary image and stored. The area of liver parenchyma was considered as the reference area and the fractional surface occupied by fibrosis (the blue area) was measured in comparison to the reference area. A 20 random fields/group was analyzed independently and the percentage of the fibrotic areas in the livers was calculated by dividing the total blue-colored areas by the total areas of the livers.

Detection of IL-10 mRNA expression in liver tissue: Detection of IL-10 mRNA expression in liver tissue of all mice groups was done by reverse transcription polymerase chain reaction (RT-PCR). Briefly, RNA isolation and purification was done using TRIZOL Reagent supplied by (Invitrogen). Purified RNA was reversely transcribed into DNA (cDNA) followed by PCR amplification using RT-PCR One Step kit supplied by QIAGEN by the following primers (3 GCA GGACTTTAAGGGTTACT5 ) \& (5'TCAT GGGCCTTGTAGACACC3`) after Abdel Ghaffar et al. (2000). Detection of PCR amplified products was done by gel electrophoresis and all positive cases were analyzed by spectrophotometer where $\mathrm{OD}=50 \mu \mathrm{g} / \mathrm{ml} \&$ concentrations were expressed in $\mathrm{ng} / \mu \mathrm{l}$.

Statistical analyses: Data were computeri- 
zed \& tabulated using mean, standard de-

Differences were significant if $\mathrm{P} \leq 0.05$. viation and chi-square test by SPSS V.16.

Results

Table 1: Percentage of stem cell engraftment into liver in groups.

\begin{tabular}{|c|c|c|c|c|}
\hline \multicolumn{2}{|c|}{ Mice groups } & GIIb & GIIc & Total \\
\hline \multirow{2}{*}{+ +VE } & Number & 15 & 16 & 31 \\
\cline { 2 - 6 } & $\%$ & 75 & 80 & 77.5 \\
\hline \multirow{2}{*}{- VE } & Number & 5 & 4 & 9 \\
\cline { 2 - 6 } & $\%$ & 25 & 20 & 22.5 \\
\hline \multirow{2}{*}{ Total } & Number & 20 & 20 & 40 \\
\cline { 2 - 6 } \multicolumn{2}{c|}{0.140} \\
\hline \multirow{2}{*}{ Chi-Square } & $\mathrm{X}^{2}$ & \multicolumn{3}{|c|}{$0.704^{*}$} \\
\cline { 2 - 5 } & $\mathrm{p}$-value & \multicolumn{5}{|c}{} \\
\hline
\end{tabular}

Table 2: Size of granulomas $(\mu) /$ liver section in groups

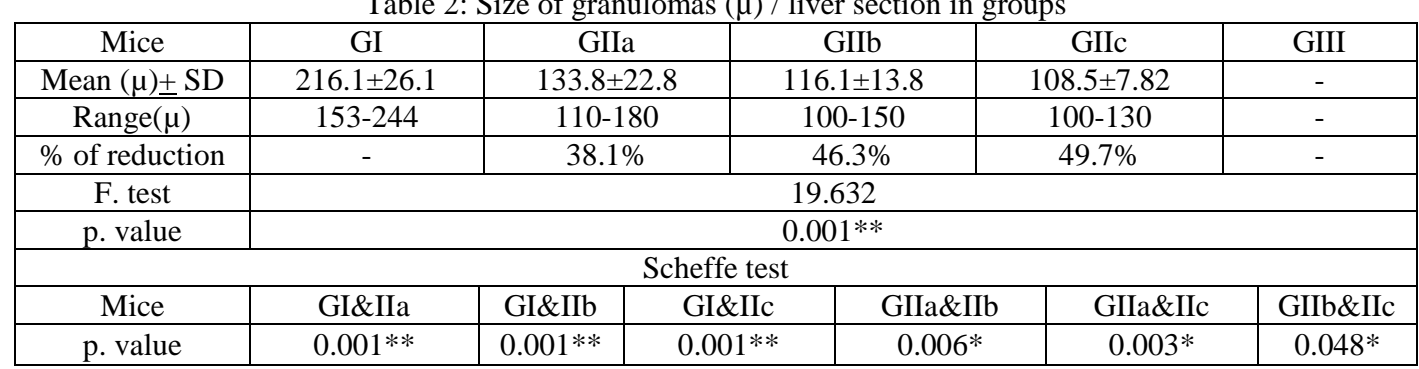

Table 3: Percentage of hepatic fibrosis groups

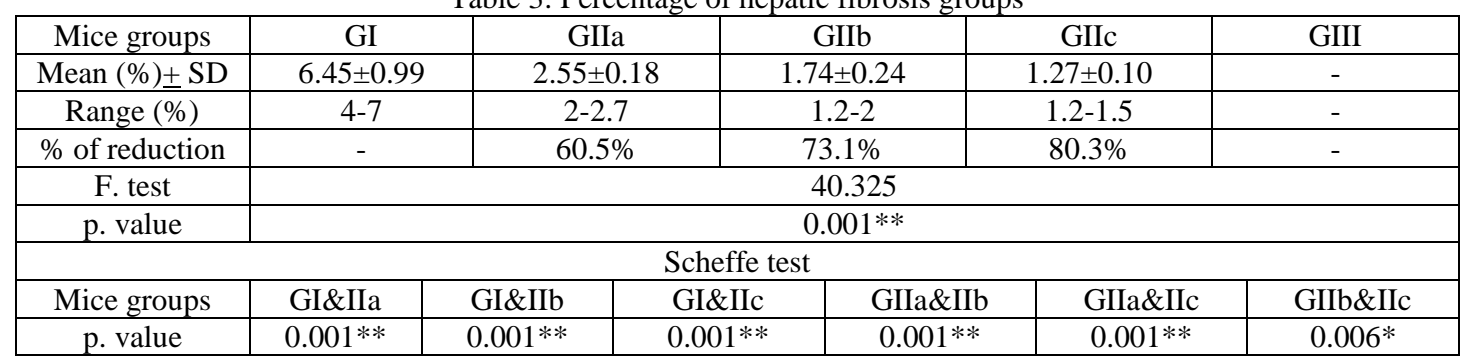

Table 4: IL-10 mRNA expression $(\mathrm{ng} / \mu \mathrm{l})$ in groups

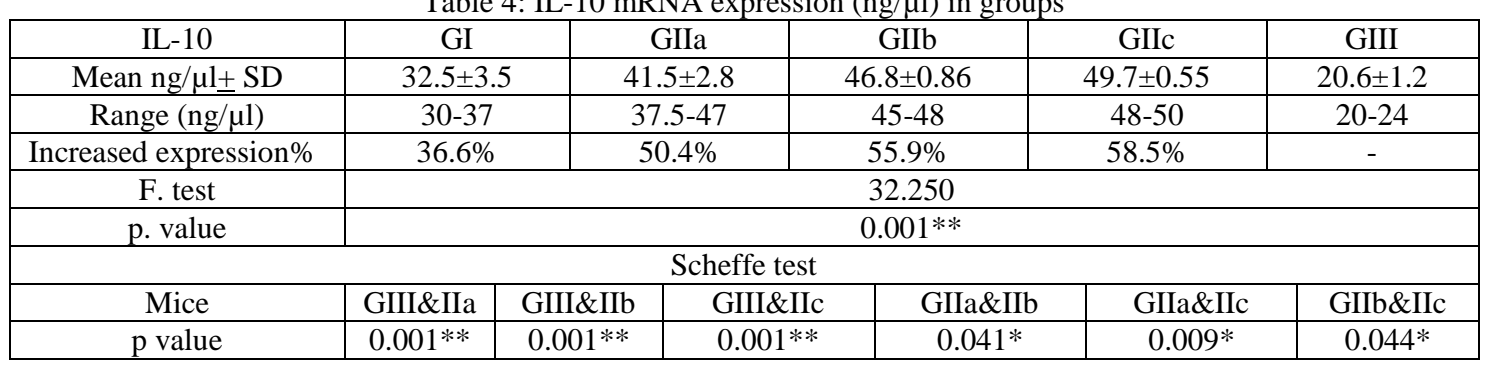

Transplanted BMSCs were found in livers of $S$. mansoni-infected mice: Presence of donor male-specific $S r y$ gene in mice groups that received BMSCs (GIIb) and GIc was confirmed, 10 wks post infection, by using PCR analysis in the livers of female recipient mice infected with $S$. mansoni (Fig. 2). In GIIb, the stem cell engraftment was $(75 \%)$, and reached (80\%) in GIIc with a total engraftment of $(77.5 \%)$ in both groups $(p=0.704)$. These results suggested that peripherally intravenously injected BMSCs were capable of liver engraftment in mice infected with $S$. mansoni (Tab. 1).

BMSCs therapy improved morphological the hepatic changes in $S$. mansoni-infected mice: Liver sections of $S$. mansoni infected mice were examined $10 \mathrm{wks}$ post infection, the GI showed a granulomatous inflammatory reaction with multiple, large sized-granulomas of cellular and fibrocellular types. The cellular granulomas showed marked collection of inflammatory cells (Fig. 3A). Some sections showed the adult worm in the 
portal tract (Fig. 3B). The inflammatory cellular infiltrate within the granulomas was of grade (IV). After the treatment with PZQ, BMSCs or both, a great positive impact was observed on schistosomal hepatic pathology, where all detected granulomas were mainly of fibrotic type with the cellular elements markedly decreased and replaced by fibrous tissue (Fig. 3C, 3D, 3E). The inflammatory cellular infiltrate within the granulomas was of GIII in mice GIIa, grade (II) in mice GIIb and grade (I) in mice GIIc (Fig. 4). Mean diameter of hepatic granulomas was significantly reduced after all types of treatment in comparison to the GI. Also, mean diameter of granulomas in GI was $216.1 \mu \pm 26.1$, and reduced to $133.8 \mu \pm 22.8$ in GIIa, $116.1 \mu \pm$ 13.8 in GIIIb and $108.5 \mu \pm 7.82$ in GIIc $(\mathrm{p}=0.001)$. Highest percentage of reduction in the mean diameter of granulomas was in both PZQ and BMSCs treated GIIc (Tab. 2). As to the hepatic parenchymal necrosis in mice groups; demonstrated in GI there was moderate hepatic parenchymal necrosis of grade (III), while in GIIa there was minimal hepatic parenchymal necrosis of grade (I) and in GIIb and GIIc no hepatic parenchymal necrosis was detected (Fig. 5).

Therapy with BMSCs reduced liver fibrosis in S. mansoni chronically infected mice: Liver sections of $S$. mansoni were analyzed. In GI, the mean percentage of hepatic fibrosis was $6.45 \% \pm 0.99$, but with significant decreased in other groups. In GIIa, mean percentage of hepatic fibrosis was s significantly decreased to $2.55 \% \pm 0.18(\mathrm{p}=0.001)$. In GIIb), mean percentage of hepatic fibrosis was significantly decreased to $1.74 \% \pm$ 0.24 ( $\mathrm{p}=0.001)$. In GIIc, mean percentage of hepatic fibrosis was significantly decreased to $1.27 \% \pm 0.10(\mathrm{p}$ value $=0.001)($ Tab. 3$)$.

Transplantation of BMSCs increased Il-10 mRNA expression: Expression of IL-10 m RNA ( $n g / \mu l)$ in all mice. In GIII, mean value of IL-10 mRNA expression was 20.6ng/ $\mu l \pm 1.2$, but was significantly increased in all other groups ( $\mathrm{p}=0.001)$. In GI, IL-10 mRNA expression increased to $32.5 \mathrm{ng} / \mu 1 \pm 3.5$, while it reached $41.5 \mathrm{ng} / \mu \mathrm{l} \pm 2.8$ in GIIa, 46.8ng/ $\mu 1 \pm 0.86$ in GIIb, $49.7 \mathrm{ng} / \mu 1 \pm 0.55$ in GIIc. Highest increased IL-10 mRNA expression was $58.5 \%$ in GIIc followed by $55.9 \%$ in GIIb, 50.4\% in GIIa and least was in GI and reached 36.6\% (Tab. 4; Fig. 6).

\section{Discussion}

Liver fibrosis and its end stage cirrhosis, represent a serious worldwide public health problem. Most patients with cirrhosis die from one or more clinical complications as ascites, hepatic encephalopathy and variceal bleeding (Bataller and Brenner, 2005). Among 1.4 million liver disease-related deaths each year worldwide, over $55 \%$ of them are directly attributed to cirrhosis (Dai et al, 2009). Many reports have demonstrated that transplantation of bone marrowderived stem cells in experimental models of hepatic fibrosis could improve liver function, decreases fibrosis index and contributes to parenchymal regeneration (Fang et al, 2004; Zhao et al, 2005; Piryaei et al, 2011). In the present study, the effects of BMSCs transplantation in a model of chronic liver disease caused by $S$. mansoni infection were given. The recruitment of BMSCs to liver lesions was recorded in several models of liver diseases (Oliveira et al, 2008, Elkhafif et al, 2010; Piryaei et al, 2011). In the present study, liver injury caused by $S$. mansoni infection elicited the migration of peripherally injected BMSCs into the livers of female recipient mice. However, in the current study, BMSCs were not detected in all liver samples. This could be attributed to the engraftment of some cells in organs other than the liver e.g. colon. Schistosomiasis is considered a systemic disease affecting organs other than the liver producing widespread tissue injuries which may have favored the migration of BMSCs to these injuredtissues. Elkhafif et al. (2010) reported that organ injury was the key factor directing the migration of systemically-injected stem cells and that no engraftment occurred when stem cells were injected into normal non-injuredmice, supported our explanation. 
Fibrosis is a common feature of the chronic liver diseases. It is characterized by increasing deposition of extracellular matrix proteins, portal hypertension due to obstruction of the blood vessels and focal ischaemic lesions. All of these features contribute to alterations in liver structure and function. Although spontaneous regression of fibrosis occurs when the stimulus for liver damage is removed, in some liver diseases e.g. viral hepatitis, the stimulus can't be completely removed in addition to being a slow process (Kumar and Sarin, 2007). Thus, schistosomiasis proved an interesting model of chronic fibrotic liver diseases even when worms die, the presence of eggs in tissues releasing soluble egg antigens contributes to continuous occurrence of many fibrotic lesions.

In the present study, there was a significant improvement of hepatic pathology after all treatment modalities (PZQ, BMSCs or both), with the best results obtained when PZQ and BMSCs were simultaneously administered. As demonstrated by reduction in granuloma size, density of inflammatory reaction and hepatic parenchymal necrosis. Also, the morphometric assessment of total liver fibrosis revealed marked reduction. Besides, as the BMSCs were administered intravenously, this reveals that fibrosis doesn't hamper the influx of cells to liver of S. mansoni-infected mice.

The improvement of hepatic fibrosis after BMSCs transplantation was also recorded by other studies (Fang et al, 2004; Zhao et al, 2005; Almeida-Porada et al, 2010). The mechanisms underlying the improvement in liver fibrosis and liver functions observed BMSCs transplantation in various experimental models of chronic hepatic injuries are still a matter of researches. Many reports have suggested that MSCs may act via paracrine secretion of factors which help in organ repair. Ozaki et al. (2002) demonstrated the ability of BMSCs to express hepatocyte growth factor (HGF) which increases the expression and activity of proteases that are involved in the breakdown of extracellular matrix. Besides, Higashiyama et al. (2007) and Chang et al. (2009) reported that the stem cell paracrine expression of the matrix metalloproteinases (MMPs) facilitated recovery from chemically-induced liver damage. So, stem cells in the fibrosis resolution. BMSCs might also have an inhibitory effect on quiescent hepatic stellate cells (main fibrogenic cells concerned with the production of extracellular matrix proteins) preventing their activation into myofibroblasts (Zhao et $a l, 2005)$. They reported also the ability of stem cells to induce apoptosis of the activated hepatic stellate cells. Thus, they prevented the fibrosis occurrence. Also, Oliveira et al. (2008) reported that TGF- $\beta$ was significantly lowered after bone marrow transplantation to mice with hepatic fibrosis. They stated that this cytokine was considered as fibrosis-promoting cytokine and its reduction denotes resolving of fibrosis.

Almeida-Porada et al. (2010) reported that a potent anti-inflammatory effect of bone marrow derived the mesenchymal stem cells when transplanted into rats with chemical fibrosis. This may explains the reduction in the density of inflammatory reaction and size of hepatic granulomas observed in the current study. Parekkadan et al. (2007) recorded that mesenchymal stem cells (MSCs) have an anti-apoptotic activity for hepatocytes and verified presence of some anti-apoptotic molecules such as the vascular endothelial growth factor and hepatocyte growth factor (HGF) in MSCs culture medium. This explained the absence of parenchymal necrosis, in mice treated with BMSCs, reported in the present study.

Improvement of liver regeneration and functions after stem cell therapy was clarified by Jung et al. (2009) who reported the differentiation of infused stem cells into hepatocyte-like cells. These hepatocyte-like cells expressed albumin and $\alpha$ fetoprotein. Also, Tsai et al. (2009) found that stem cell engraftment in liver was associated with an increase in prolactin hormone which was linked to liver regeneration. Also, Fang et al. 
(2004) noticed an increase in the number of oval cells (hepatic progenitor cells), they attributed this increase in the number of oval cells to the ability of stem cells to stimulate resident oval cells to proliferate and replace areas where fibrosis degradation occurs. So, stem cells may promote liver repair via prevention of hepatocyte apoptosis together with replacement of damaged hepatocytes by normal functioning cells.

In the present study, using PZQ drugs caused significant improvement in hepatic pathology. But, the best improvement was obtained when both PZQ and BMSCs were given together. The mechanism of action of PZQ in schistosomiasis was studied by many authors who stated that PZQ treatment mainly affects the adult schistosomes causing their paralysis and destruction. Hence, egg deposition and subsequently associated fibrosis is dramatically decreased. These authors added that PZQ had a potent antifibrotic and anti-inflammatory effect (Caffrey, 2007; El-Lakkany et al, 2012). This may explain the improvement of hepatic fibrosis with PZQ treatment, observed in the current study. And the best results were obtained when BMSCs were given with PZQ, this could be referred to the elimination of adult worms by PZQ and reduction of fibrosis by BMSCs.

Cytokines, mainly those produced by Th2 cells, have a very important role in schistosomiasis. They can help in controlling the pathology of schistosomal granulomas by the production of a state of the immunemodulation decreasing both inflammation and fibrosis, thus contributing to less adjacent tissue injury (Von Boehmer, 2005). One of the chief soluble mediators with known immune-regulatory functions that induced early after exposure to schistosome cercariae, was IL-10 (Hogg et al, 2003).

Interleukin-10 is a cytokine which has wide range regulatory effects upon antigen presentation, co-stimulation and development of acquired $\mathrm{T}$ cell responses. This immune-regulatory effect is highly beneficial to patients suffering from schistosomiasis concerning regulation of the inflammatory response against egg deposition that may cause more aggressive pathology, with reduction of granuloma size and influx of inflammatory cells (Moore et al, 2001). It was also found that the transgenic mice overexpressing Il-10 from hepatocytes shown to be protected from fibrosis. This proved the anti-fibrogenic properties of this cytokine (Muddu et al, 2007).

In the present study, IL-10 mRNA expression was measured as an anti-fibrotic related marker and to determine if the used therapy performed its anti-fibrotic action via IL-10. According to the current study, all treatment modalities caused significant increase in IL10 mRNA expression with the highest increase in mice received both PZQ and BMSCs. The present findings coincide with those of Wilson et al. (2011) who recorded increase in IL-10 producing cells following PZQ therapy using IL-10 green fluorescent protein reporter mice. Also, Parekkadan et al. (2007) found that co-culture of mesenchymal stem cells (MSCs) and hepatic stellate cells (HSCs) caused apoptosis of HSCs and marked reduction of collagen production by these cells. When MSCs were devoid of their IL-10, they lost their effect on HSCs. This highlights that stem cells may exhibit reactions via paracrine mechanisms involving IL-10.

In the present study, BMSCs were engrafted into injured livers, improved fibrosis percentage, and decreased hepatic granulomas size with mild inflammatory reactions and non- parenchymal necrosis and provoked the production of immune-regulatory IL-10 cytokine. When combined with the PZQ gave good results. It was hypothesized that these cells acted via paracrine secretion of factors that degraded the extracellular matrix proteins. Moreover, they mostly produced an immune-modulatory environment that decreased the tissue inflammatory reaction together with protection of the residual hepatocytes from apoptosis as observed by the 
absence of hepatic parenchymal necrosis. But, many aspects offering the grounds for optimism in this concern were discovered recently, the most important is that British scientists not only proved that stem cells could produce hepatocytes, and have grown the world's first artificial liver from umbilical cord blood stem cells (Jurga et al, 2010).

\section{Conclusion}

The outcome results showed that BMSCs improved schistosomal hepatic fibrosis specially when combined with PZQ in a mice model raising the possibility for their clinical use after assurance of their safety. Stem cell research, in spite of the great progress in the last few years, is still in its infancy and more in-depth studies are needed. Thus, there is a great hope that stem cell therapy may be the golden key for all patients suffering from end stage liver diseases after the assurance of their complete safety.

\section{Acknowledgements}

The authors are grateful to Professor Dr. Mouhamed Sobh, Director of Medical Experimental Research Center, Mansoura University, and Mr. Samah Awad, Veterinarian for kind animal care assistance. Thanks also extended to Mr. Mahmoud Elhussini for providing technical assistance during cultivation of BMSCs.

\section{References}

Abdalla, AF, Zalata, KhR, Ismail, AF, Shiha, G, Attiya, M, et al, 2009: Regression of fibrosis in paediatric autoimmune hepatitis: morphometric assessment of fibrosis versus semiquantiatative methods. Fibr. Tiss. Rep. 2:2-8.

Abdel Aziz, M, Atta, H, Roshdy, N, Rashed, L, Sabry, D, et al, 2012: Amelioration of murine Schistosoma mansoni induced liver fibrosis by mesenchymal stem cells. J. Stem Cells Regen. Med. 8:28-34.

Abdel Ghaffar, AE, Deyab, FA, Khalifa, EA, 2000: Cytokine production (IL-2 \& IL-10) and their roles in schistosomal hepatic granuloma for-mation in experimental animals. Egyp. J. Med. Microbiol. 9:739-44.

Ali, SA, Hamed, MA, 2006: Effect of Ailanthus altissima and Zizyphus spinachristi on bilharzial infection in mice: histological and histopathological studies. J. App. Sci. 6:1437-46.
Almeida-Porada, G, Zanjani, ED, Porada, C D, 2010: Bone marrow stem cells and liver regeneration. Exp. Hematol. 38:574-80.

Andrade, ZA, Cheever, AW, 1993: Characterization of the murine model of schistosomal hepatic periportal fibrosis ('pipestem' fibrosis). Int. J. Exp. Pathol. 74:195-202.

Bataller, R, Brenner, DA, 2005. Liver fibrosis. J. Clin. Invest. 115:209-18.

Botros, SS, Mahmoud, MR, Moussa, MM, Nosseir, MM, 2007: Immunohistopathological and biochemical changes in Schistosoma manso$n i$-infected mice treated with artemether. J. Infect. 55:470-7.

Caffrey, CR, 2007: Chemotherapy of schistosomiasis: present and future. Curr. Opin. Chem. Biol. 11:433-9.

Chang, YJ, Liu, JW, Lin, PC, Sun, LY, Peng, CW, et al, 2009: Mesenchymal stem cells facilitate recovery from chemically induced liver damage and decrease liver fibrosis. Life Sci. 85:517-25.

Cho, KA, Ju, SY, Cho, SJ, Jung, YJ, Woo, S Y, et al, 2009: Mesenchymal stem cells showed the highest potential for the regeneration of injured liver tissue compared with other subpopulations of the bone marrow. Cell Biol. Int. 33: 772-7.

Dai, LJ, Li, HY, Guan, LX, Ritchie, G, Zhou, JX, 2009: The therapeutic potential of bone marrow-derived mesenchymal stem cells on hepatic cirrhosis. Stem Cell Res. 2:16-25.

Dobson, KR, Reading, L, Haberey, M, Marine, X, Scutt, A, 1999: Centrifugal isolation of bone marrow from bone: an improved method for the recovery and quantification of bone marrow osteoprogenitor cells from rat tibiae and femurae. Calcif. Tissue Int. 65:411-3.

Elkhafif, N, Voss, B, Hammam, O, Yehia, H, Mansy, S, et al, 2010: Homing of transplanted bone marrow cells in livers of Schistosoma mansoni-infected mice. A.P.M.I.S. 118:277-87.

El-Lakkany, NM, Hammam, OA, El-Maadawy, WH, Badawy, AA, Ain-Shoka, AA, et al, 2012: Anti-inflammatory/anti-fibrotic effects of the hepatoprotective silymarin and the schistosomicide praziquantel against Schistosoma mansoni-induced liver fibrosis. Parasit. Vect. 11:5-9. Fang, B, Shi, M, Liao, L, Yang, S, Liu, Y, Zhao, RC, 2004: Systemic infusion of FLK1-mesenchymal stem cells ameliorate carbon tetrachloride-induced liver fibrosis in mice. Transplant. 78: 83-8. 
Farid, A, Al-Sherbiny, M, Osama, A, 2005: Schistosoma infection inhibits cellular immune responses to core HCV peptides. Parasit. Immunol. 27:189-96.

Freeman Jr, RB, Steffick, DE, Guidinger, M K, Farmer, DG, Berg, CL, et al, 2008: Liver and intestine transplantation in the United States, 1997-2006. Am. J. Transplant. 8:958-76.

Friedman, SL, 2003: Liver fibrosis-from bench to bedside. Hepatol. 38:S38-53.

George, K, Michalopoulos, LB, William, CB, 2005: Transdifferentiation of rat hepatocytes into biliary cells after bile duct ligation and toxic biliary injury. Hepatol. 41:535-44.

Higashiyama, R, Inagaki, Y, Hong, YY, Kushida, M, Nakao, S, et al, 2007: Bone marrowderived cells express matrix metalloproteinases and contribute to regression of liver fibrosis in mice. Hepatol. 45:213-22.

Hogg, KG, Kumkate, S, Mountford, A, 2003: IL-10 regulates early IL-12-mediated immune responses induced by the radiation-attenuated schistosome vaccine. Int. Immunol. 15:1451-9.

Ishak, K, Baptista, A, Bianchi, L, 1995: Histologic grading and staging of chronic hepatitis. Hepatol. 22:696-9.

Ismail, HIH, Farrag, AKT, Abo-Raya, AA, 2001: Pygeum africanum as an inhibitor for fibrogenesis: does it have a role in experimental hepatic schistosomal granuloma. Egyp. J. Med. Microb-iol. 10:533-42.

Jung, KH, Shin, HP, Lee, S, Lim, YJ, Hwang, SH, et al, 2009: Effect of human umbilical cord blood-derived mesenchymal stem cells in a cirrhotic rat model. Liver Int. 29:898-909.

Jurga, M, Forraz, N, McGuckin, CP, 2010: Artificial human tissues from cord and cord blood stem cells for multi-organ regenerative medicine: viable alternatives to animal in vitro toxicology. Altern. Lab. Anim. 38:183-92.

Kumar, M, Sarin, SK, 2007: Is cirrhosis of the liver reversible? Indian J. Pediatr. 74:393-9.

Mbaye, A, Appleton, CC, 2001: Praziquantel quality, dosages and markers of resistance. Trends Parasitol. 17:356-7.

Moore, KW, De Waal Malefyt, R, Coffman, $R$ L, O'Garra, A, 2001: Interleukine-10 and the interleukine-10 receptor. Annu. Rev. Immunol. 19: 683-765.

Muddu, AK, Guha, IN, Elsharkawy, AM, Mann, DA, 2007: Resolving fibrosis in the diseased liver: translating the scientific promise to the clinic. Int. J. Biochem. Cell Biol. 39:695714.

Oliveira, SA, Souza, BSF, Guimaraes-Ferreira, CA, Barreto, ES, Souza, SC, et al, 2008: Therapy with bone marrow cells reduces liver alterations in mice chronically infected by Schistosoma mansoni. World J. Gastroenterol. 14: 5842-50.

Ozaki, I, Zhao, G, Mizuta, T, Ogawa, Y, Hara, T, et al, 2002: Hepatocyte growth factor induces collagenase (matrix metalloproteinase-1) via the transcription factor Ets-1 in human hepatic stellate cell line. Hepatol. 36:169-78.

Parekkadan, B, Van Poll, D, Megeed, Z, Kobayashi, N, Tilles, AW, et al, 2007: Immunomodulation of activated hepatic stellate cells by mesenchymal stem cells. Biochem. Biophys. Res. Commun. 363:247-52.

Piryaei, A, Valojerdi, MR, Shahsavani, M, Baharvand, H, 2011: Differentiation of bone marrow-derived mesenchymal stem cells into hepatocyte-like cells on nanofibers and their transplantation into a carbon tetrachloride-induced liver fibrosis model. Stem Cell Rev. 7:103-18.

Saez-Lara, MJ Frecha, C, Martin, F, Abadia, F, Toscano, M, et al, 2006: Transplantation of human CD34 stem cells from umbilical cord blood to rats with thioacetamide-induced liver cirrhosis. Xenotransplant. 13:529-35.

Tsai, PC, Fu, TW, Chen, YM, Ko, TL, Chen, T H, et al, 2009: The therapeutic potential of human umbilical mesenchymal stem cells from Wharton's jelly in the treatment of the rat liver fibrosis. Liver Transpl. 15:484-95.

Von Boehmer, H, 2005: Mechanisms of suppression by suppressor $\mathrm{T}$ cells. Nat. Immunol. 6 : 338-44.

Wilson, MS, Cheever, AW, White, SD, Thompson, RW, Wynn, TA, 2011: IL-10 blocks the development of resistance to re-infection with Schistosoma mansoni. PLoS Path. 7: e1002171.

Wu, G, Liu, N, Rittelmeyer, I, Sharma, DA,

Sgodda, M, et al, 2011: Generation of healthy mice from gene-corrected disease-specific induced pluripotent stem cells. PLoS Biol. 9:e1001099 (1-14).

Zhao, DC, Lei, JX, Chen, R, Yu, WH, Zhang, $\mathrm{XM}$, et al, 2005: Bone marrow-derived mesenchymal stem cells protect against experimental liver fibrosis in rats. World J. Gastroenterol. 11: 3431-40. 


\section{Explanations to figures}

Fig. 1A: Rounded glistening BMSCs on second day of culture.

Fig. 1B: BMSCs one week after cultivation. Majority acquired fibroblastic spindle shape morphology.

Fig. 2: PCR analysis of Sry gene in liver of experimental mice 10 weeks post infection, $800 \mathrm{bp}$ band in male normal liver. No signal was detected in control (GI), a distinct band in GIIb \& GIIc.

Fig. 3A: Liver section of GI (control infected, non-treated) showing multiple schistosomal granulomas. Some of cellular types while others fibrocellular. Some showed $S$. mansoni ova (H\&E 100X).

Fig. 3B: Liver section of an infected female mouse GI showed adult $S$. mansoni in portal tract (H\&E 200X).

Fig. 3C: Liver section of GIIa showed one small well defined granuloma surrounding S. mansoni ovum (MT 100X).

Fig. 3D: Liver section of GIIb (BM MSCs-treated) showing one small well defined granuloma (MT 100X).

Fig. 3E: Liver section of GIIc (PZQ+BM MSCs-treated) showing minute bluish bands of fibrous tissue with lack of significant fibrosis (MT 100X)

Fig. 4: Relation between grades of inflammatory reaction within hepatic granulomas in groups. Grade I: $\leq 25 \%$ Grade II: $25 \%$-50\% Grade III: $51 \%$ $75 \%$ Grade IV: $>75 \%$

Fig. 5: Relation between the grades of hepatic parenchymal necrosis in groups. Grade I: < 2 necrotic foci / lobule Grade II: 2-5 necrotic foci / lobule Grade III: 6-10 necrotic foci / lobule Grade IV: > 10 necrotic foci / lobule.

Fig. 6: Gel electrophoresis of IL-10 mRNA expressions in groups showing positive bands at $242 \mathrm{bp}$.
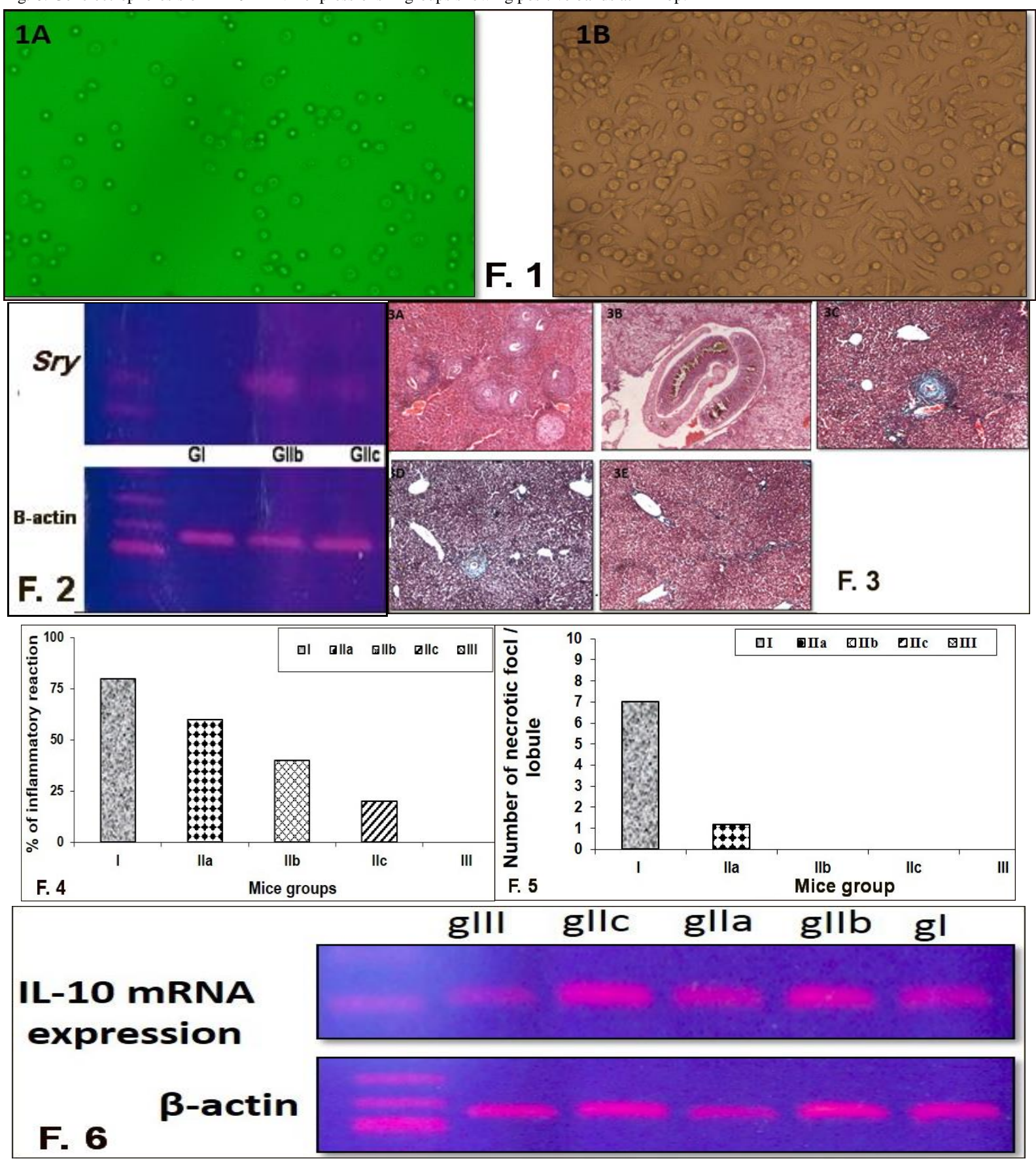